\title{
Simple Sensorless Control of Interior Permanent Magnet Synchronous Motor Using PLL Based on Extended EMF
}

\author{
Dong Yeob Han*, Yongsoo Cho** and Kyo-Beum Lee ${ }^{\dagger}$
}

\begin{abstract}
This paper proposes an improved sensorless control to estimate the rotor position of an interior permanent magnet synchronous motor. A phase-locked loop (PLL) is used to obtain the phase angle of the grid. The rotor position can be estimated using a PLL based on extended electromotive force (EEMF) because the EEMF contains information about the rotor position. The proposed method can reduce the burden of calculation. Therefore, the control period is decreased. The simulation and experimental results confirm the effectiveness and performance of the proposed method.
\end{abstract}

Keywords: Interior permanent magnet synchronous motor, Extended electromotive force, Sensorless control, Phase-locked loop

\section{Introduction}

The permanent magnet synchronous motor (PMSM) has no additional power source to generate flux because the rotor of the PMSM is made of a permanent magnet. Therefore, the efficiency of the total system is increased by reducing its power consumption. A PMSM has no copper loss in its rotor because the rotor is not powered. A PMSM is used in various applications requiring a high-efficiency motor. The performance of a PMSM is determined according to the type of its permanent magnet. The characteristics of a PMSM depend on the arrangement and shape of the permanent magnet. Based on the arrangement of the permanent magnet, a PMSM is fundamentally divided into an interior permanent magnet synchronous motor (IPMSM) and a surface-mounted permanent magnet synchronous motor (SPMSM). Because the magnet is mounted inside the rotor, an IPMSM is durable during high-speed operation compared with a SPMSM [1-4].

The speed control of an IPMSM requires information about the rotor position and speed. An encoder and resolver are used to measure the rotor position and speed. However, the sensor that measures the rotor position has a problem with reliability because the sensor can generate errors such as high temperature or mechanical vibration. The error can be included in the measured rotor position by high temperature or mechanical vibration. Moreover, the IPMSM drive system has an additional circuit to set the sensor. Because of the additional circuit, the total system becomes more expensive and mechanically voluminous $[5,6]$. Therefore, various control methods for the IPMSM have been researched to detect the rotor position without a

$\dagger \quad$ Corresponding Author: Dept. of Electrical and Electronic Engineering, Ajou University, Korea. (kyl@ajou.ac.kr)

* Carrier, Seoul, Korea. (dongyeob.han@carrier.co.kr)

** LG Electronics, Seoul, Korea. (ys1.cho@lge.com)

Received: July 1, 2016; Accepted: October 28, 2016 sensor [7-13].

Sensorless control methods are classified into two types. The first type is based on the electromotive force (EMF) machine model [14]. The second type is high-frequency (HF) signal injection estimation [15]. The mathematical model of an IPMSM using extended electromotive force (EEMF) is a sensorless control method. Errors in the rotor position are determined by estimating the EEMF because the EEMF contains information about the rotor position [16]. A least-order observer is used to estimate the EEMF.

In a grid system, the phase angle of the grid can be obtained by using a phase-locked loop (PLL). The proposed method utilizes a controller based on a PLL to estimate the rotor position and speed. The rotor position can be estimated by controlling the $d$-axis EEMF to be zero because information about the rotor position is included in the $d$-axis contained in the EEMF. An IPMSM drive system using the proposed method can reduce the burden of calculation. By reducing the calculation burden, the control period becomes shorter. Experimental and simulation results are offered to verify the effectiveness of the proposed method.

\section{Modeling of IPMSM}

Fig. 1 shows the space vector diagram of the IPMSM. Three different reference frames are displayed in Fig. 1. The stationary reference frame is the $\alpha-\beta$ reference frame, and the synchronous rotating frame is the $d-q$ reference frame synchronized to the rotor. The reference frame is the estimated rotating frame.

Eq. (1) is the voltage equation of the IPMSM on the $d-q$ synchronous rotating reference frame.

$$
\left[\begin{array}{l}
v_{d} \\
v_{q}
\end{array}\right]=\left[\begin{array}{cc}
R+p L_{d} & -\omega_{r} L_{q} \\
\omega_{r} L_{d} & R+p L_{q}
\end{array}\right]\left[\begin{array}{l}
i_{d} \\
i_{q}
\end{array}\right]+\left[\begin{array}{c}
0 \\
\omega_{r} \cdot k_{E M F}
\end{array}\right]
$$




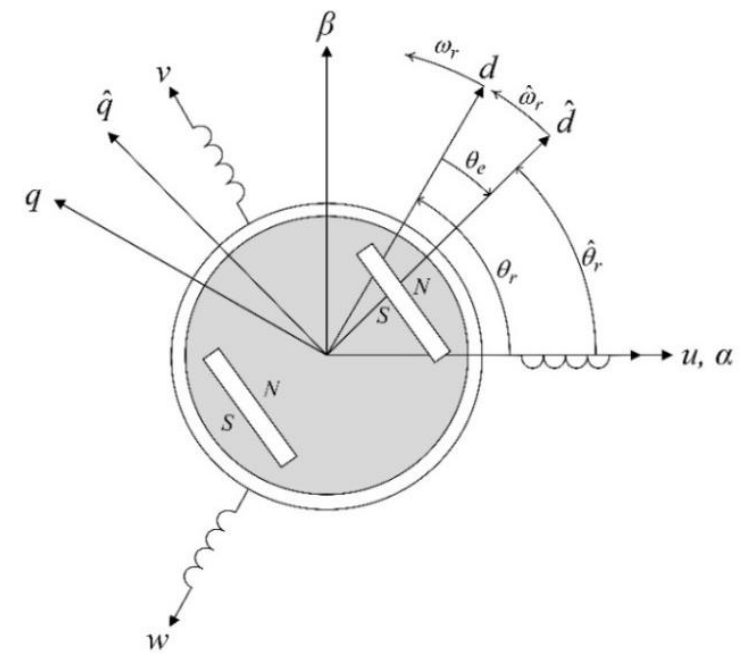

Fig. 1. Space vector diagram of IPMSM.

where

$v_{d}, v_{q}$ : voltage in synchronous reference frame

$i_{d}, i_{q}$ : current in synchronous reference frame

$\omega_{r} \quad:$ rotor angular velocity

$p \quad:$ differential operator

$k_{\mathrm{EMF}}: \mathrm{EMF}$ constant

$L_{d}, L_{q}: d-q$ axis inductance

$R$ : stator resistor.

The voltage equation on the $\alpha-\beta$ stationary reference frame is derived by transforming (1):

$$
\left[\begin{array}{c}
v_{\alpha} \\
v_{\beta}
\end{array}\right]=\left[\begin{array}{cc}
R+p L_{\alpha} & p L_{\alpha \beta} \\
p L_{\alpha \beta} & R+p L_{\beta}
\end{array}\right]\left[\begin{array}{l}
i_{\alpha} \\
i_{\beta}
\end{array}\right]+\omega_{r} k_{E M F}\left[\begin{array}{c}
-\sin \theta_{r} \\
\cos \theta_{r}
\end{array}\right]
$$

where

$$
\begin{aligned}
& L_{\alpha}=L_{0}+L_{1} \cos 2 \theta_{r}, \quad L_{\beta}=L_{0}-L_{1} \cos 2 \theta_{r} \\
& L_{\alpha \beta}=L_{1} \sin 2 \theta_{r} \\
& L_{0}=\left(L_{d}+L_{q}\right) / 2, \quad L_{1}=\left(L_{d}-L_{q}\right) / 2 \\
& v_{\alpha}, v_{\beta}: \text { voltage in stationary reference frame } \\
& i_{\alpha}, i_{\beta}: \text { current in stationary reference frame } \\
& \theta_{r}: \text { rotor position. }
\end{aligned}
$$

It is difficult to solve (2) mathematically because (2) contains both the $\theta_{r}$ and $2 \theta_{r}$ terms. In order to analyze the modeling of the IPMSM, (2) can be expressed as (3) by dividing the $\theta_{r}$ and $2 \theta_{r}$ terms:

$$
\begin{aligned}
{\left[\begin{array}{l}
v_{\alpha} \\
v_{\beta}
\end{array}\right] } & =\left(R+p L_{0}\right)\left[\begin{array}{l}
i_{\alpha} \\
i_{\beta}
\end{array}\right]+\omega_{r} k_{E M F}\left[\begin{array}{l}
-\sin \theta_{r} \\
\cos \theta_{r}
\end{array}\right] \\
& +p L_{1}\left[\begin{array}{rr}
\cos 2 \theta_{r} & \sin 2 \theta_{r} \\
\sin 2 \theta_{r} & -\cos 2 \theta_{r}
\end{array}\right]\left[\begin{array}{l}
i_{i} \\
i_{\beta}
\end{array}\right]
\end{aligned}
$$

Since the magnitudes of $L_{d}$ and $L_{q}$ are identical, $L_{1}$ becomes zero in the SPMSM. Therefore, (3) can be easily solved by removing the $2 \theta_{r}$ term in the SPMSM. However,
$L_{1}$ becomes a value other than zero because the magnitudes of $L_{\mathrm{d}}$ and $L_{\mathrm{q}}$ are different in the IPMSM. If it is possible to ignore the harmonics generated by the inverter, the current of the motor does not include the secondary harmonic. Therefore, the $2 \theta_{r}$ terms can be removed from the pure mathematical method. By eliminating the $2 \theta_{r}$ terms, the voltage equation in the $d-q$ synchronous rotating reference frame can be rewritten as follows (4):

$$
\begin{aligned}
{\left[\begin{array}{l}
v_{d} \\
v_{q}
\end{array}\right] } & =\left[\begin{array}{cc}
R+p L_{d} & -\omega_{r} L_{q} \\
\omega_{r} L_{q} & R+p L_{d}
\end{array}\right]\left[\begin{array}{l}
i_{d} \\
i_{q}
\end{array}\right] \\
& +\left[\begin{array}{c}
0 \\
\left(L_{d}-L_{q}\right)\left(\omega_{r} i_{d}-i_{q}\right)+\omega_{r} k_{E M F}
\end{array}\right]
\end{aligned}
$$

where the second term on the right side of (4) is the EEMF by (5):

$$
E E M F=\left(L_{d}-L_{q}\right)\left(\omega_{r} i_{d}-i_{q}\right)+\omega_{r} k_{E M F}
$$

By transforming (4), the voltage equation on the $\alpha-\beta$ stationary reference frame is obtained as follows:

$$
\begin{aligned}
{\left[\begin{array}{c}
v_{\alpha} \\
v_{\beta}
\end{array}\right] } & =\left[\begin{array}{cc}
R+p L_{d} & \omega_{r}\left(L_{d}-L_{q}\right) \\
-\omega_{r}\left(L_{d}-L_{q}\right) & R+p L_{d}
\end{array}\right]\left[\begin{array}{c}
i_{\alpha} \\
i_{\beta}
\end{array}\right] \\
& +\left\{\left(L_{d}-L_{q}\right)\left(\omega_{r} i_{d}-i_{q}\right)+\omega_{r} k_{E M F}\right\}\left[\begin{array}{c}
-\sin \theta_{r} \\
\cos \theta_{r}
\end{array}\right]
\end{aligned}
$$

The $2 \theta_{r}$ terms does not exist in (6). The voltage equation for the estimated synchronous reference frame can be defined as follows:

$$
\left[\begin{array}{l}
v_{\widehat{d}} \\
v_{\widehat{q}}
\end{array}\right]=\left[\begin{array}{cc}
R+p L_{d} & -\omega_{r} L_{q} \\
\omega_{r} L_{q} & R+p L_{d}
\end{array}\right]\left[\begin{array}{l}
i_{\widehat{d}} \\
i_{\hat{q}}
\end{array}\right]+\left[\begin{array}{l}
e_{\widehat{d}} \\
e_{\widehat{q}}
\end{array}\right]
$$

where the second term on the right side of (7) is expressed as follows:

$$
\left[\begin{array}{l}
e_{\widehat{d}} \\
e_{\widehat{q}}
\end{array}\right]=E E M F\left[\begin{array}{c}
-\sin \theta_{e} \\
\cos \theta_{e}
\end{array}\right]+\left(\widehat{\omega}_{r}-\omega_{r}\right) L_{d}\left[\begin{array}{c}
-i_{\hat{d}} \\
i_{\widehat{q}}
\end{array}\right]
$$

This modeling of the IPMSM is very simple in comparison with (1). The EEMF is utilized to estimate the rotor position and speed because the EEMF contains information about the rotor position and speed.

\section{Method for Estimating Rotor Position}

\subsection{Estimating the EEMF}

A least-order observer is used to estimate the EEMF [16]. If the error between the actual rotor speed and the estimated rotor speed is approximated to zero, the EEMF is estimated as (9): 


$$
\left[\begin{array}{l}
\hat{e}_{\hat{d}} \\
\hat{e}_{\hat{q}}
\end{array}\right]=E E M F\left[\begin{array}{c}
-\sin \hat{\theta}_{e} \\
\cos \hat{\theta}_{e}
\end{array}\right]
$$

\subsection{Proposed method for estimating rotor position}

The estimated error of the rotor position $\hat{\theta}_{e}$ is represented as (10) in the estimated $\hat{d}-\hat{q}$ rotating reference frame using the EEMF:

$$
\widehat{\theta}_{e}=\tan ^{-1}\left(-\frac{\hat{e}_{\hat{d}}}{\hat{e}_{\hat{q}}}\right)
$$

Eq. (10) is used to estimate the rotor position in the conventional method [16]. Many algorithms were derived from (10) such as [17] and [18]. If the $d$-axis estimated EEMF $\hat{e}_{\hat{d}}$ becomes zero, the estimated rotor position error $\hat{\theta}_{\hat{e}}$ becomes zero. Moreover, $\hat{e}_{\hat{d}}$ can be linearized to the estimated rotor position error as (11) because rotor position $\theta_{r}$ seems to be equal to $\sin \theta_{r}$ for a satisfactorily small angle:

$$
\begin{aligned}
& \hat{e}_{\hat{d}}=E E M F\left(-\hat{\theta}_{e}\right) \\
& \hat{e}_{\hat{q}}=E E M F
\end{aligned}
$$

The error of the rotor position can be defined as follows (12) by the $d$-axis estimated EEMF error:

$$
\begin{aligned}
\hat{e}_{\hat{d} \_ \text {error }} & =e_{d}-\hat{e}_{\hat{d}} \\
& =-\operatorname{EEMF}\left(-\hat{\theta}_{e}\right) \\
& =\operatorname{EEMF}\left(\theta_{r}-\hat{\theta}_{r}\right)
\end{aligned}
$$

A block diagram for estimating the rotor position is shown in Fig. 3. If the process of coordinate transformation is ideal and the cut-off frequency of a low-pass filter (LPF) is set much higher than the response frequency of the system controller, the block diagram in Fig. 3 can be

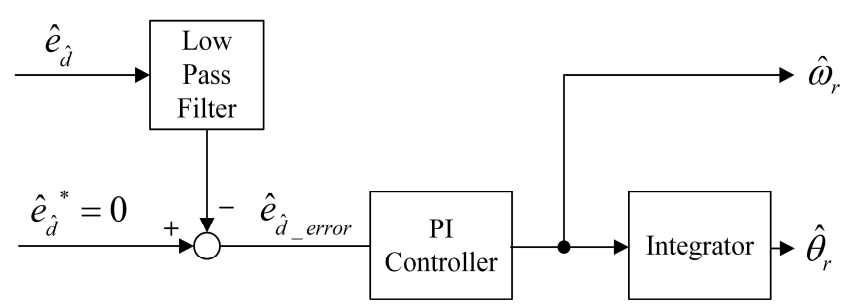

Fig. 2. Block diagram for estimating rotor position and speed.

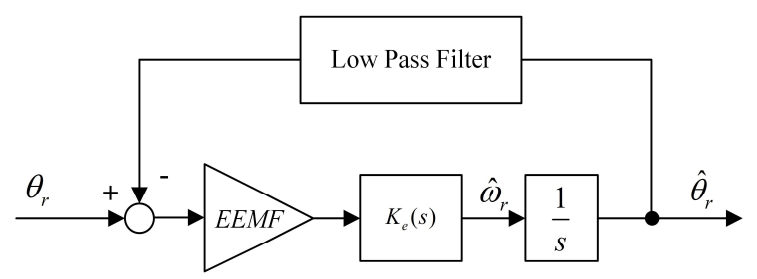

Fig. 3. Linearized estimation model. simply modeled. Fig. 4 shows a linearized estimation model for the rotor position. The LPF is designed as a 1storder system with cut-off frequency $\omega_{c c}$ as follows (13):

$$
K_{L P F}(s)=\frac{\omega_{c c}}{s+\omega_{c c}}
$$

The open-loop transfer function is equal to (14), and Eq. (15) represents the closed-loop transfer function:

$$
\begin{gathered}
T(s)=E E M F \cdot K_{p}\left(\frac{1+s \tau}{s \tau}\right) \cdot \frac{1}{s} \\
H_{c}=\frac{T(s)}{1+T(s) \cdot K_{L P F}(s)}
\end{gathered}
$$

Eq. (16) can be rewritten as a general 3rd-order transfer function as follows (17):

$$
\begin{aligned}
H_{c_{-} \text {model }}= & \frac{s+\alpha}{s+\alpha} \cdot \frac{2 \zeta \omega_{n} s+\omega_{n}^{2}}{s^{2}+2 \zeta \omega_{n} s+\omega_{n}^{2}} \\
& \omega_{c c}=1+2 \zeta \omega_{n}
\end{aligned}
$$

where $\omega_{n}$ is the system bandwidth, and $\zeta$ is the damping coefficient.

If $\alpha$ is equal to 1 , the proportional gain and time constant of a PI-type controller can be obtained as (18):

$$
K_{p}=\frac{2 \zeta \omega_{n}}{E E M F}, \tau=\frac{E E M F \cdot K_{p} \cdot \omega_{c c}}{\omega_{n}^{2}}
$$

The proposed estimation method for the rotor position can estimate the rotor position without the division term. The proposed method can also reduce the control period because the calculation burden is decreased.

\section{Simulation and Experiment Results}

\subsection{Simulation results}

A simulation is conducted using the PSIM simulation tool to verify the performance of the proposed method. A three-level inverter is used to operate the IPMSM. The specifications for the IPMSM are listed in Table 1. Fig. 4 shows the control block diagram of the total system. The speed of the motor is controlled to be the reference speed by the speed controller. The reference current is the output of the speed controller. The reference voltage for the space vector pulse-width modulation is decided by the current controller. The reference voltage and current are used to estimate the position of the rotor by using the rotor position and speed estimator.

Fig. 5 shows the performance of the proposed method according to the load. The reference of the rotor speed is fixed to be $300 \mathrm{rpm}$. The estimate d rotor angle is matched 
Table 1. Specifications for the simulation

\begin{tabular}{c|c|c}
\hline Parameter & Value & Unit \\
\hline Rated power & 11 & $\mathrm{~kW}$ \\
\hline Rated speed & 1450 & $\mathrm{rpm}$ \\
\hline Rated voltage & 191 & $\mathrm{~V}$ \\
\hline Rated current & 38 & $\mathrm{~A}$ \\
\hline Stator resistance & 0.099 & $\Omega$ \\
\hline$d$-axis inductance & 4.07 & $\mathrm{mH}$ \\
\hline$q$-axis inductance & 4.65 & $\mathrm{mH}$ \\
\hline Poles & 6 & - \\
\hline Switching frequency & 10 & $\mathrm{kHz}$ \\
\hline Input voltage & 400 & $\mathrm{~V}$ \\
\hline
\end{tabular}

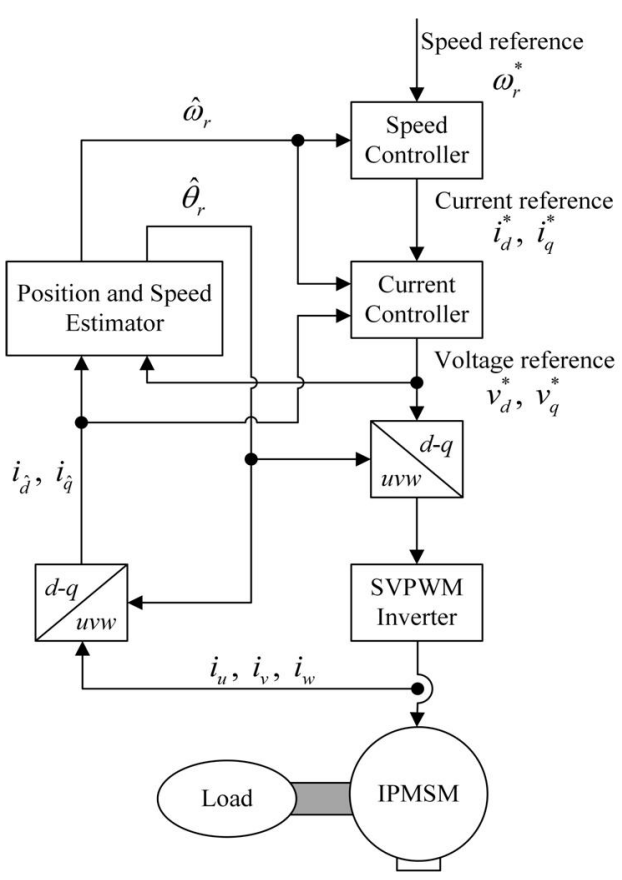

Fig. 4. Control block diagram of proposed sensorless speed control system.

to the actual rotor angle without the delay. The estimated angle error with a $30 \%$ load is less than the estimated angle error with no load because the EEMF with a $30 \%$ load is larger than the EEMF with no load.

The performance of the proposed method according to changes in rotor speed is shown in Fig. 6 . At $6 \mathrm{~s}$, the reference of the rotor speed is changed from $300 \mathrm{rpm}$ to $500 \mathrm{rpm}$. When the reference of the rotor speed is changed, the estimated angle error increases, but the magnitude of the increase is less than $0.1 \mathrm{rad}$.

\subsection{Experiment results}

Fig. 7 shows the experiment set. A three-phase induction motor is used as the load motor. A three-level inverter generates the reference voltage to operate the IPMSM. The control board is composed of a TMS320F28335 micro control unit. The system parameters are the same as those in the simulation. In order to control the speed and torque of the motor, the estimated information of the rotor
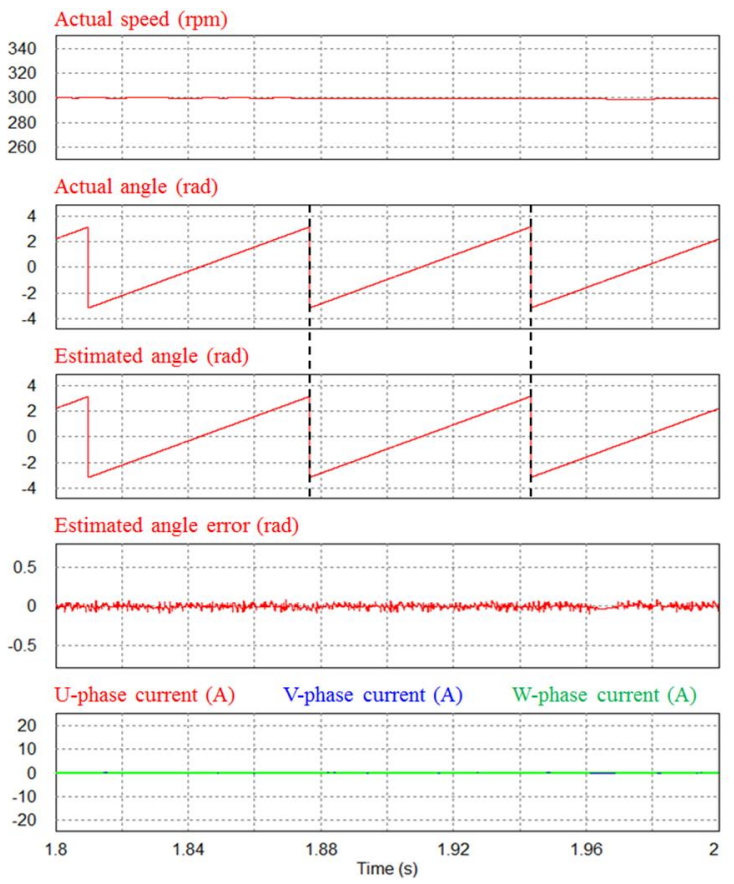

(a)

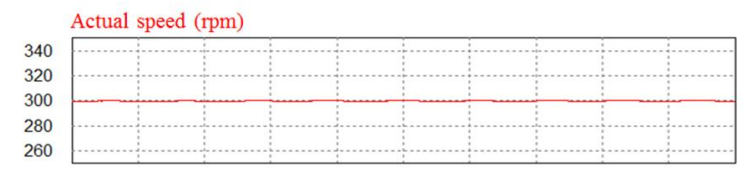

Actual angle (rad)

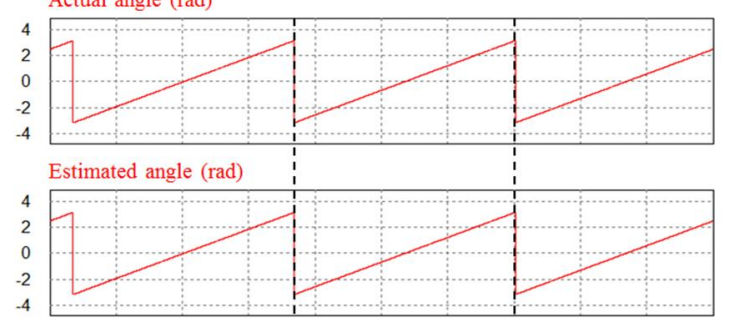

Estimated angle error (rad)
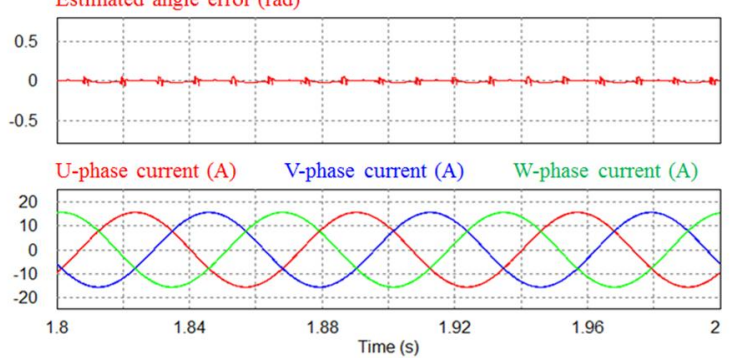

(b)

Fig. 5. Performance of proposed method according to load: (a) no load and (b) $30 \%$ load.

position is used. The actual information of the rotor position could be obtained by the encoder. It is only used to compare with the proposed method from Fig. 8 to Fig. 12.

Fig. 8 shows a comparison of the control period between the conventional method and the proposed method. The control period of the proposed method is approximately $17 \%$ less than the control period of the conventional method because the calculation burden of the proposed 


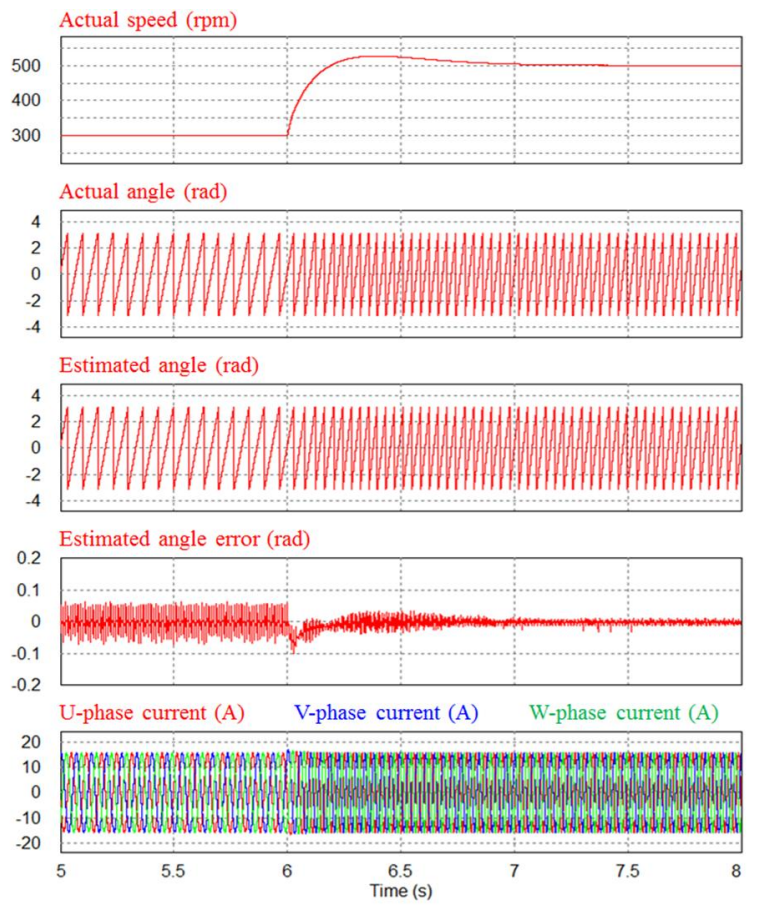

Fig. 6. Performance of proposed method according to changes in rotor speed.

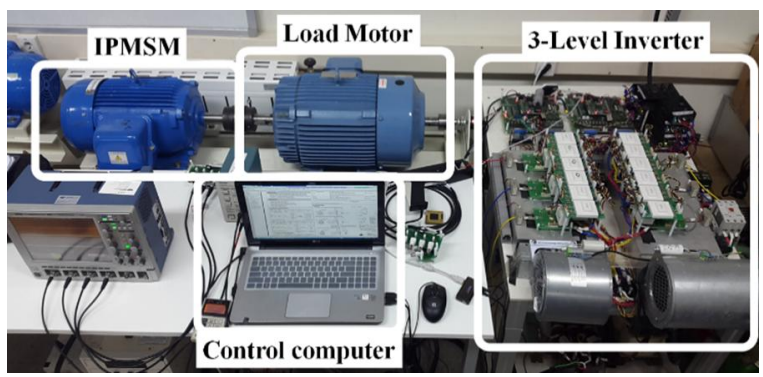

Fig. 7. Experiment set.

method is less than that of the conventional method.

The performance of the proposed method is shown in Fig. 9 and 10. The experimental conditions are $300 \mathrm{rpm}$ with no load and $500 \mathrm{rpm}$ with a $30 \%$ load. In both conditions, the rotor speed is precisely controlled without oscillation because the estimated rotor angle accurately estimates the actual rotor angle with no delay. The error of the estimated rotor angle is less than $0.1 \mathrm{rad}$.

Fig. 11 shows the performance of the proposed method according to the change from $300 \mathrm{rpm}$ to $500 \mathrm{rpm}$. When the rotor speed is changed from $300 \mathrm{rpm}$ to $500 \mathrm{rpm}$, the reference current is increased to generate torque for the acceleration. The error of the estimated rotor angle is generated in the section where the rotor speed changed because the proposed method estimates the rotor position by using the reference current and voltage. However, the magnitude of the error is less than $0.2 \mathrm{rad}$.

Fig. 12 shows the performance according to the change in torque. The rotor speed reference is $300 \mathrm{rpm}$, and the

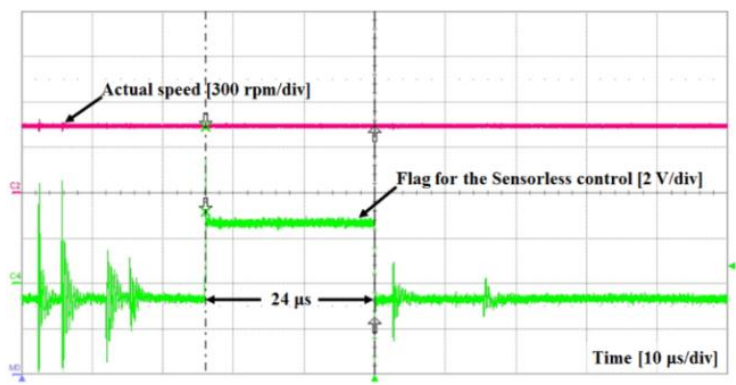

(a)

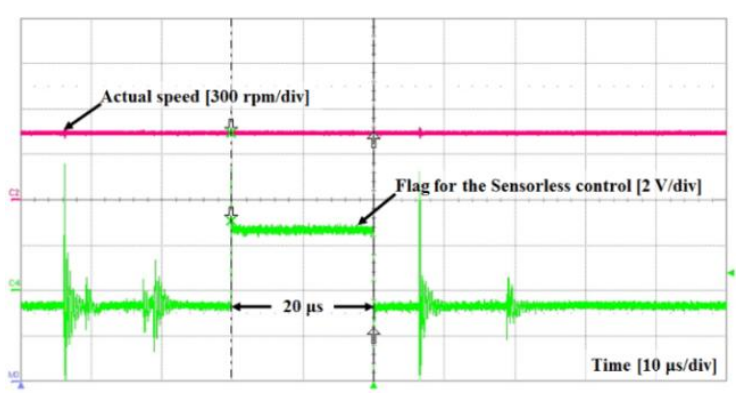

(b)

Fig. 8. Control period comparison: (a) conventional method and (b) proposed method.

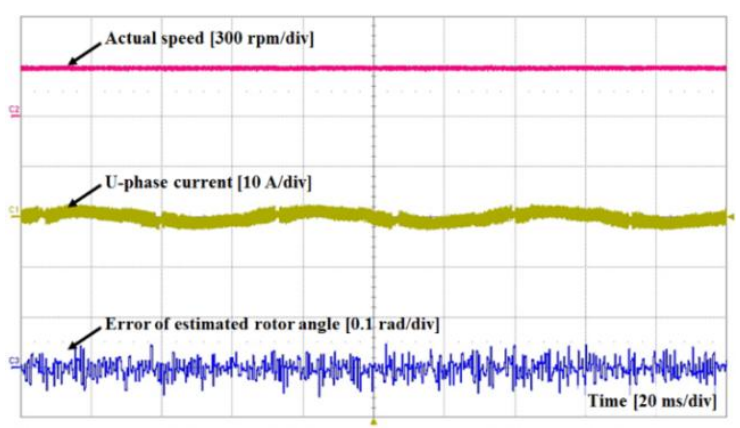

(a)

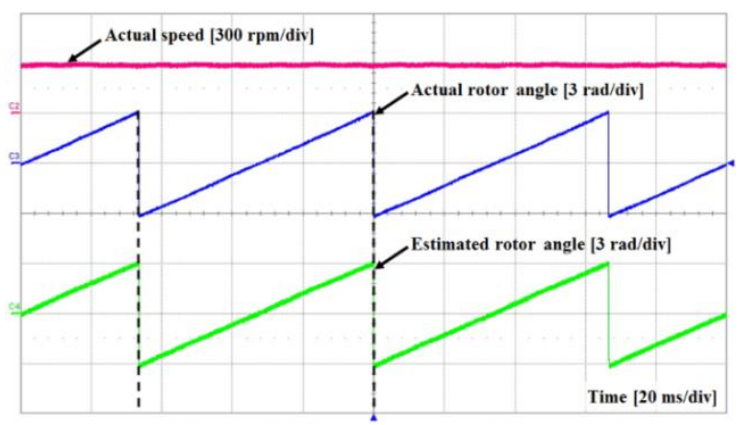

(b)

Fig. 9. Estimation of rotor position with no load at $300 \mathrm{rpm}$ : (a) u-phase current and error of estimated rotor angle and (b) comparison between actual rotor angle and estimated rotor angle.

magnitude of the load change is $30 \%$. An oscillation is generated to control the current because the reference current changes according to the load change. The error 
in the estimated rotor angle is clearly oscillated in the section where the rotor speed changes because the amount of change in the EEMF is larger than that in the speed-

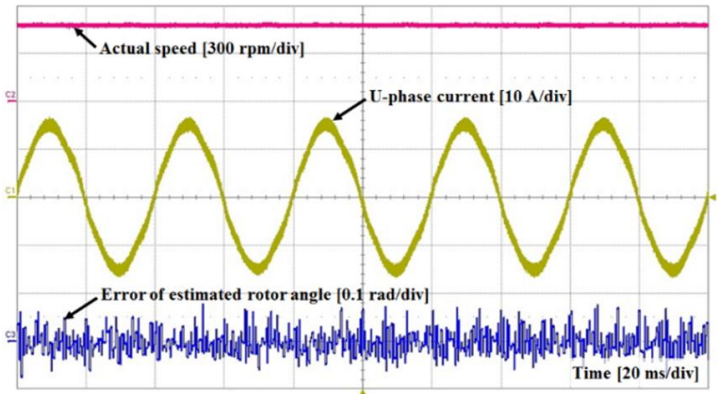

(a)

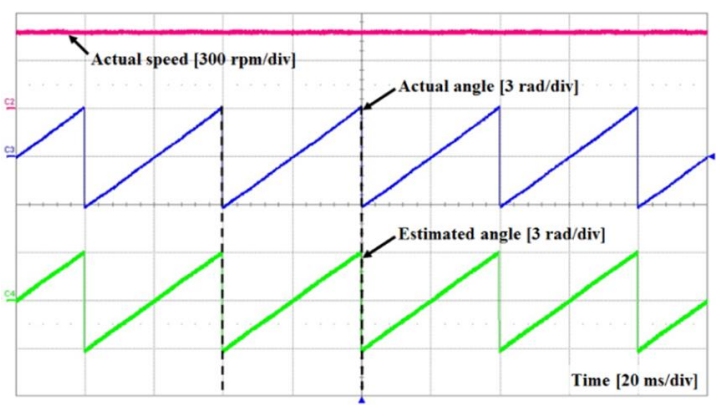

(b)

Fig. 10. Estimation of rotor position with $30 \%$ load at 500 rpm: (a) u-phase current and error of estimated rotor angle and (b) comparison between actual rotor angle and estimated rotor angle.

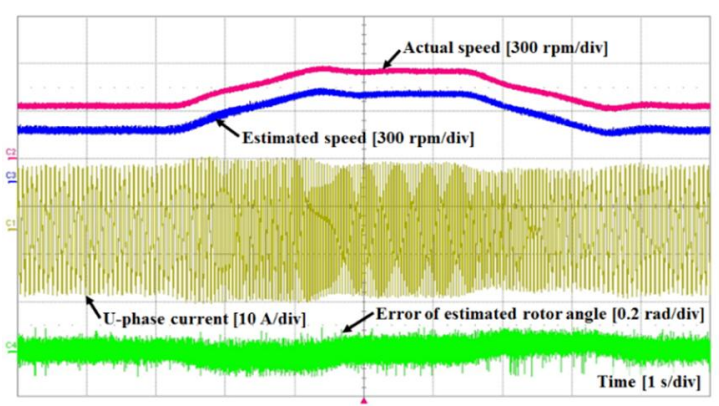

Fig. 11. Performance of proposed method according to change in speed.

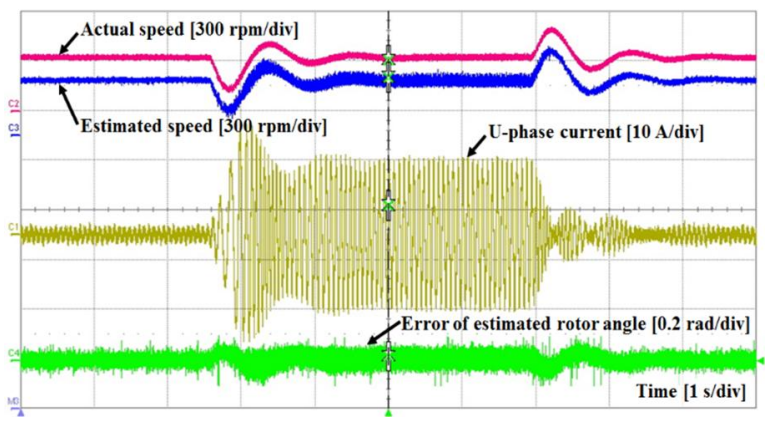

Fig. 12. Performance of proposed method according to change in torque. change experiment. The sensorless speed control performs effectively: the error of the estimated rotor angle is less than $0.2 \mathrm{rad}$.

\section{Conclusion}

This paper proposed an improved estimation method for the sensorless control of an IPMSM based on a PLL. An EEMF is used to estimate the rotor position because the EEMF contains information about the rotor position. The conventional method uses a division term such as an arctangent to obtain information about the rotor position. The proposed method uses a PLL-type controller to estimate the error between the actual rotor angle and the estimated rotor angle by controlling the estimated $d$-axis extended EMF to be zero. The control period is reduced because the calculation burden is decreased. A 16-bit MCU can accurately control the rotor speed by using the proposed method. The results of the simulation and experiment were presented to verify the effectiveness of the proposed method.

\section{Acknowledgements}

This research was supported by Basic Science Research Program through the National Research Foundation of Korea (NRF) funded by the Ministry of Science, ICT \& Future Planning (2016R1A2B4010636).

\section{References}

[1] J. M. Kim and S. K. Sul, "Speed Control of Interior Permanent Magnet Synchronous Motor Drive for the Flux Weakening Operation," IEEE Trans. Ind. Appl., vol. 33, no. 1, pp. 43-48, Jan./Feb. 1997.

[2] S. M. Kim, Y. D. Yoon, and S. K. Sul, "Maximum Torque per Ampere (MTPA) Control of an IPM Machine Based on Signal Injection Considering Inductance Saturation," IEEE Trans. Power Electron., vol. 28, no. 1, pp. 488-497, Jan. 2013.

[3] Y. S. Cho, K. B. Lee, J. H. Song, and Y. I. Lee, "Torque-Ripple Minimization and Fast Dynamic Scheme for Torque Predictive Control of Permanent Magnet Synchronous Motors," IEEE Trans. Power Electron., vol. 30, no. 4, pp. 2182-2190, Apr. 2015.

[4] H. Kim, J. Hartwig, and R. Lorenz, "Using On-Line Parameter Estimation to Improve Efficiency of IPM Machine Drives," in Proc. IEEE Power Electron. Spec. Conf., vol. 2, pp. 815-820, 2002.

[5] Y. Zhao, W. Qiao, and L. Wu, "An Adaptive QuasiSliding-Mode Rotor Position Observer-Based Sensorless Control for Interior Permanent Magnet Synchronous Machines," IEEE Trans. Power Electron., 
vol. 28, no. 12, pp. 5618-5629, Dec. 2013.

[6] R. Wrobel, A. S. Budden, D. Salt, D. Holliday, P. H. Mellor, A. Dinu, and P. Sangha, "Rotor Design for Sensorless Position Estimation in Permanent Magnet Machines," IEEE Trans. Ind. Electron., vol. 58, no. 9, pp. 3815-3824, Sep. 2011.

[7] G. Wang, R. Yang, and D. Xu, "DSP-Based Control of Sensorless IPMSM Drives for Wide-Speed-Range Operation," IEEE Trans. Ind. Electron., vol. 60, no. 2, pp. 720-727, Feb. 2013.

[8] G. Foo and M. Rahman, "Sensorless Sliding-Mode MTPA Control of an IPM Synchronous Motor Drive Using a Sliding-Mode Observer and HF Signal Injection," IEEE Trans. Ind. Electron., vol. 57, no. 4, pp. 1270-1278, Apr. 2010.

[9] Y. Mao, J. Yang, D. Yin, and Y. Chen, "Sensorless IPMSM Control Based on an Extended Nonlinear Observer with Rotational Inertia Adjustment and Equivalent Flux Error Compensation," J. Power Electron., vol. 16, no. 6, pp. 2150-2161, Nov. 2016.

[10] T. M. Yoon, J. S. Lee, and K. B. Lee, "Rotor Position Estimation Method of IPMSM Using HF Signal Injection and Sliding-Mode Controller," IEEJ Trans. Electr. Electron. Eng., vol. 9, no. S1, pp. S56-S63, Oct. 2014.

[11] C. H. Hong, J. Lee, and D. M. Lee, "Sensorless Scheme for Interior Permanent Magnet Synchronous Motors with a Wide Speed Control Range," J. Power Eletron., vol. 16, no. 6, pp. 2173-2181, Nov. 2016.

[12] K. G. Lee, J. S. Lee, and K. B. Lee, "Wide-Range Sensorless Control for SPMSM Using an Improved Full-Order Flux Observer," J. Power Eletron., vol. 15, no. 3, pp. 721-729, May 2015.

[13] D. Y. Han, Y. S. Cho, and K. B. Lee, "Simple Rotor Position Estimation for Sensorless Control of IPMSM Using PLL Based on EEMF", in Proc. IEEE ITEC Asia-Pacific, pp.1-5, June 2016.

[14] Z. Chen, M. Tomita, S. Doki, and S. Okuma, "An Extended Electromotive Force Model for Sensorless Control of Interior Permanent Magnet Synchronous Motors," IEEE Trans. Ind. Electron., vol. 50, no. 2, pp. 288-295, Apr. 2003.

[15] G. D. Andreescu, C. I. Pitic, F. Blaabjerg, and I. Boldea, "Combined Flux Observer with Signal Injection Enhancement for Wide Speed Range Sensorless Direct Torque Control of IPMSM Drives," IEEE Trans. Energy Convers., vol. 23, no. 2, pp. 393402, Jun. 2008.

[16] S. Morimoto, K. Kawamoto, M. Sanada, and Y. Takeda, "Sensorless Control Strategy for SalientPole PMSM Based on Extended EMF in Rotating Reference Frame," IEEE Trans. Ind. Appl., vol. 38, no. 4, pp. 1054-1061, Jul./Aug. 2002.

[17] L. Jingbo, T. A. Nondahl, P. B. Schmidt, S. Royak, and M. Harbaugh, "Rotor position estimation for synchronous machines based on equivalent EMF,"
IEEE Trans. Ind. Appl., vol. 47, no. 3, pp. 1310-1318, May/Jun. 2011.

[18] S. Y. Kim, C. Choi, K. Lee, and W. Lee, "An improved rotor position estimation with vector-tracking observer in PMSM drives with low-resolution halleffect sensors," IEEE Trans. Ind. Electron., vol. 58, no. 9, pp. 4078- 4086, Sep. 2011.

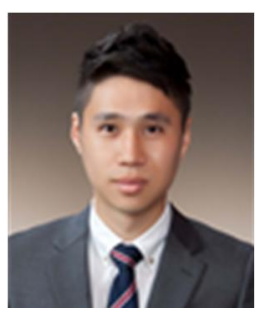

Dong Yeob Han received the B.S. degree in electrical and computer engineering from Ajou University, Suwon, South Korea, in 2014 and the M.S. degree in Space Survey Information Technology, Ajou University, Suwon, South Korea, in 2016. Since 2016, he has been with the Carrier, Seoul, Korea His research interests include motor drives and gridconnected systems.

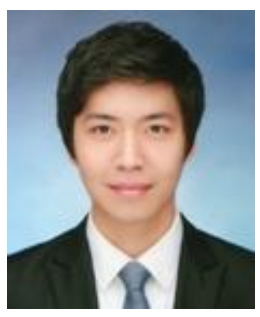

Yongsoo Cho received the B.S. and Ph.D. degree in electrical and computer engineering from Ajou University, Suwon, Korea, in 2012 and 2016. Since 2016, he has been with the LG Electronics, Seoul, Korea, as a Senior Research Engineer. His research interests include electric machine drives, gridconnected system, and power conversion.

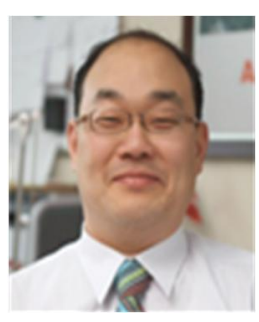

Kyo-Beum Lee received the B.S. and M.S. degrees in electrical and electronic engineering from the Ajou University, Suwon, Korea, in 1997 and 1999, respectively, and the Ph.D. degree in electrical engineering from the Korea University, Seoul, Korea, in 2003. From 2003 to 2006, he was with the Institute of Energy Technology, Aalborg University, Aalborg, Denmark. From 2006 to 2007, he was with the Division of Electronics and Information Engineering, Chonbuk National University, Jeonju, Korea. In 2007, he joined the School of Electrical and Computer Engineering, Ajou University. His research interests include electric machine drives, renewable power generations, and electric vehicle applications. Dr. Lee is an Associate Editor of the IEEE TRANSACTIONS ON POWER ELECTRONICS, the Journal of Power Electronics, and the Journal of Electrical Engineering and Technology. 